\title{
MODELLING AND CONTROL OF A VARIABLE-SPEED SWITCHED RELUCTANCE GENERATOR BASED WIND TURBINE
}

\author{
D. McSwiggan ${ }^{(1)}$, L. Xu ${ }^{(1)}$, T. Littler ${ }^{(1)}$
}

(1) Queen's University Belfast, UK

\begin{abstract}
This paper studies the system modelling and control aspects of Switched Reluctance Generator (SRG) based variable speed wind turbines. A control system is implemented to provide proper operation of the SRG as well as power tracking capabilities for varying wind speeds. The control system for the grid side inverter that will allow the SRG to properly generate power to the system is also presented. Studies are presented of both the SRG and inverter control systems capabilities during a balanced three-phase fault. The paper will demonstrate that the SRG based wind turbine presents a feasible variable wind speed solution with good fault response capabilities.
\end{abstract}

Keywords: Switched reluctance generators, converters, faults.

\section{INTRODUCTION}

The majority of wind turbines currently under development are based on doubly-fed induction generators (DFIG). However, due to their limited rotor converter rating, DFIGs may have serious problems with over currents during voltage dips [1]. Furthermore, the multi stage gearbox that the DFIG must incorporate is unreliable and expensive.

The shortcomings of the DFIG have turned research attention to more simple and robust variable speed generator topologies such as the permanent magnet (PM) generator and the focus of this paper, the switched reluctance machine (SRM).

The SRM operates on the principle of torque production through the tendency of the machines rotor to align itself to a position where inductance is at a maximum [2].

As demonstrated in Figure 1, the SRM can act as a switched reluctance generator (SRG) when the phase windings are excited during a period of falling inductance [2].

Although many publications on SRMs are in circulation, there are few publications on the use of an SRG for wind applications. In [3], a SRG based variable speed wind turbine connected to an AC grid was discussed. However, system studies presented were carried out under normal or steady state conditions.

This paper will examine the dynamic response of an SRG based wind turbine system during normal wind variation and system fault conditions.

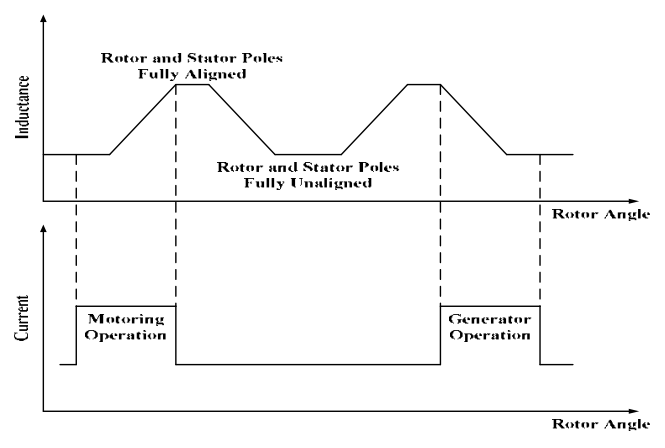

Figure 1 SRM Inductance and Current Waveforms

\section{CONTROL SYSTEM}

A schematic diagram of an SRG based wind turbine system is shown in Figure 2. The control system is based on the control of two separate power converters. The SRG converter regulates the wind turbine to allow maximum power extraction for varying wind profiles. The second converter or grid side inverter regulates the DC link voltage to allow energy from the SRG to be delivered to the system.

\subsection{Variable Wind Speed Modelling}

The mechanical power produced by a wind turbine is given by the relationship,

$$
P_{m}=\frac{1}{2} C_{p}(\Lambda, \beta) \pi \rho R^{2} V^{3}
$$

where $C_{p}(\Lambda, \beta)$ is the power coefficient, $\rho$ is the air density, $V$ is the wind speed, $R$ is the blade radius, $\beta$ is the blade pitch angle and $\Lambda$ is the tip speed ratio [3], [4]. 


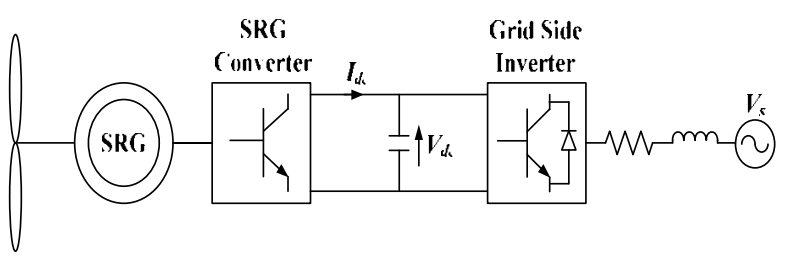

Figure 2 SRG Wind Turbine System

The tip speed ratio can be defined as,

$$
\Lambda=\frac{\omega_{r} R}{V}
$$

where $\omega_{r}$ is the mechanical rotor speed [3].

In Figure 3, various wind speeds are shown. The optimal power extraction curve intersects each wind speed at the point of maximum power capture. The profile of the optimal power curve can be expressed as,

$$
P_{o p t}=k_{\text {opt }} \omega_{r}^{3}
$$

where $k_{\text {opt }}$ is a gain based on the wind turbine's wind parameters [3], [4].

\subsection{SRG Converter}

As shown in Figure 4, the SRG converter uses a hysteresis controller with inputs taken from both rotor speed and rotor position $\theta_{r}$.

According to Figure 1, SRG operation is achieved during falling inductance levels. The position control module uses rotor position to detect periods of falling inductance and instructs the hysteresis controller to energise the corresponding phase. While the phase is energised the current level is determined by $I_{r e f}$ which is generated by the optimal power tracking module.

When a phase is energised, the DC link capacitor $C_{d c}$ initially acts as a voltage source. When the phase is deenergised, stored current returns to $C_{d c}$ as generated power.

\subsection{Grid Side Inverter}

As shown in Figure 5, the primary aim of the grid side inverter is to regulate the DC link voltage to allow the active power generated by the SRG to be transmitted to the system.

The inverter is a standard voltage source PWM based system. The control method employs the use of $d-q$ reference frames, in which the $d$ frame is fixed to the system voltage $V_{s}$ which rotates at the synchronous system speed [5]. This allows active power to be controlled by the inverter direct current component $i_{s d}$, while the inverter's quadrature current component $i_{s q}$ controls reactive power.

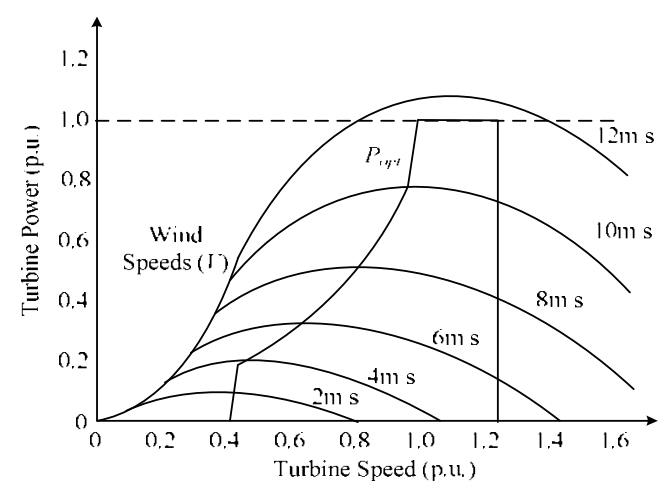

Figure 3 Wind Profile

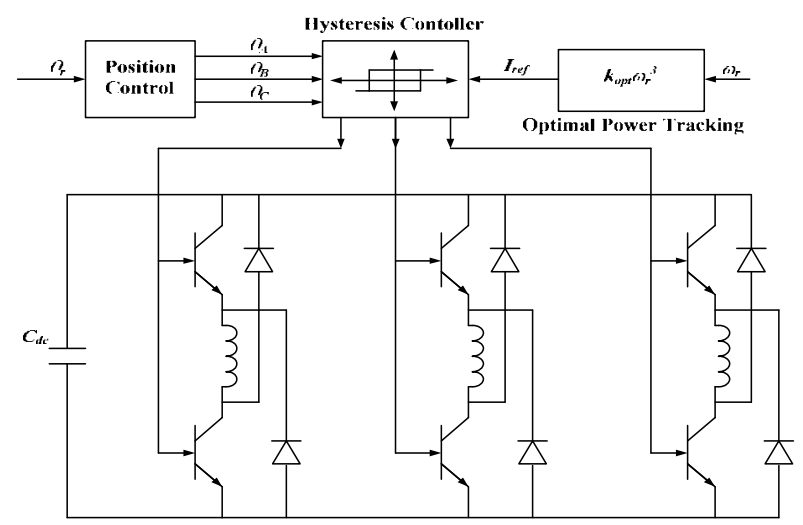

Figure 4 SRG Converter

The proposed decoupled control system was implemented through the use of two separate control loops.

The inner loop's function is to create the required modulation indexes, $\left(M_{d}\right.$ and $\left.M_{q}\right)$ for the inverter's PWM system.

By defining auxiliary inputs as,

$$
\left[\begin{array}{l}
u_{d} \\
u_{q}
\end{array}\right]=\left[\begin{array}{l}
d i_{s d} / d t \\
d i_{s q} / d t
\end{array}\right]
$$

where $u_{d}$ and $u_{q}$ are the outputs of PI controllers used to decrease error, the modulation indexes can be determined,

$$
\begin{aligned}
& M_{d}=\frac{2}{V_{d c}}\left(L_{s} u_{d}+R i_{s d}-L_{s} \omega_{s} \cdot i_{s q}+v_{s d}\right) \\
& M_{q}=\frac{2}{V_{d c}}\left(L_{s} u_{q}+R_{s} i_{s q}+L_{s} \omega_{s} \cdot i_{s d}+v_{s q}\right)
\end{aligned}
$$

where $L_{s}$ and $R_{s}$ are the inductance and resistance between the source and inverter, $\omega_{s}$ is the synchronous speed and $V_{d c}$ is the DC link voltage. 


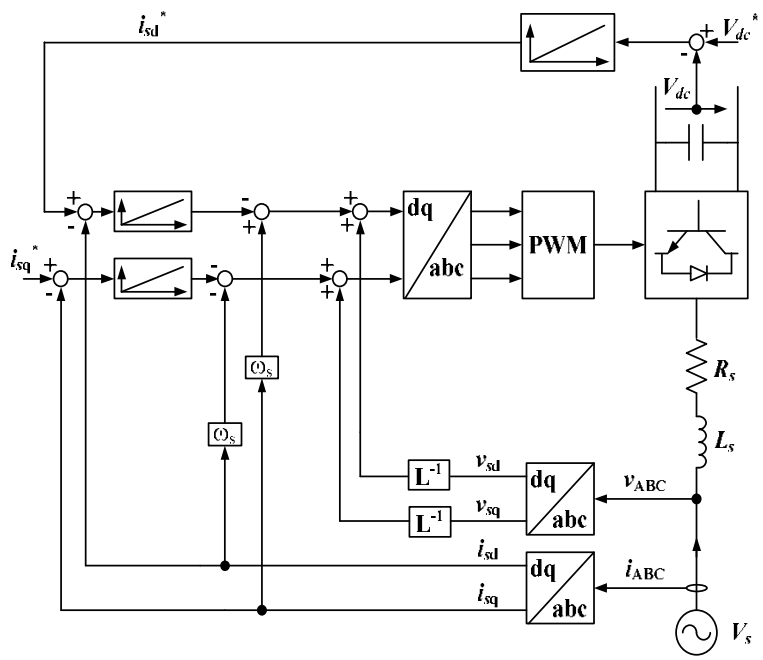

Figure 5 Grid Side Inverter Control Scheme

The outer loop's function is to maintain the DC link voltage to ensure that power generated from the SRG is balanced when it is transmitted to the system.

A PI controller was implemented to reduce errors from transients in the DC link voltage. The controller was designed as follows,

$$
i_{e}=\frac{d V_{d c}}{d t}=k_{p 2}\left(V_{d c}{ }^{*}-V_{d c}\right)+k_{i 2} \int\left(V_{d c}^{*}-V_{d c}\right) d t
$$

where $k_{p 2}$ and $k_{i 2}$ are the proportional and integral gains of the controller respectively and $V_{d c}{ }^{*}$ is the reference voltage. The outer control loop establishes the reference current $i_{s d}{ }^{*}$ according to,

$$
i_{s d}^{*}=\frac{2 C_{d c}}{3 M_{d}}\left(i_{e}+\frac{I_{d c}}{C_{d c}}-\frac{3 M_{q} i_{q}}{4 C_{d c}}\right)
$$

where $I_{d c}$ is the DC link current.

\subsection{SRG Fault Controller}

When a fault occurs, the system voltage will decrease. Consequently, the grid side inverter's power export capabilities are reduced and it is no longer able to control the DC voltage. If the power generated by the SRG is not reduced accordingly, the SRG based wind turbine would have to trip due to DC over voltage.

To prevent system trips during a fault, as shown in Figure 6, a controller was designed to alleviate the problem.

The fault hysteresis controller monitors DC link voltage, once $V_{d c}$ increases to $10 \%$ of its nominal value during a fault, control of $I_{r e f}$ is switched from the optimal power tracking module to a PI controller and the inverter's $i_{s d}$ current is set to $0.5 i_{\text {sd }}{ }^{*}$ max .

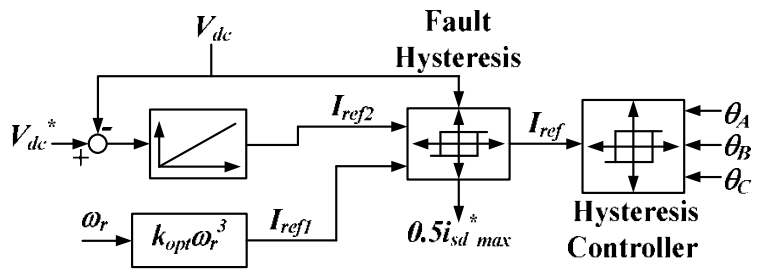

Figure 6 Fault Hysteresis Controller

The PI controller is designed to regulate the DC voltage to the nominal value by adjusting $I_{r e f}$. This in effect reduces the power generated by the SRG during the fault. With the inverter's $i_{s d}$ current set to half of its capabilities, control of the DC voltage relies entirely on the SRG. During a fault, the electrical torque of the SRG decreases, the rotor will begin to accelerate as the mechanical torque is much greater than the electrical torque.

Once the fault clears the system voltage can recover and since $i_{s d}$ is equal to $0.5 i_{s d \text { max }}{ }^{*}$ the system power can increase and $V_{d c}$ will begin to fall. When $V_{d c}$ drops to under $4 \%$ of its nominal value, the fault hysteresis controller returns control of $I_{\text {ref }}$ to the optimal power tracking module and allows the inverter's DC voltage controller to determine $i_{s d}$.

\section{SIMULATION RESULTS}

The control strategies outlined above have been implemented using the SIMULINK power systems block set. The SRG is a $6 / 4$, three-phase, $6 \mathrm{~kW}$ machine model. The grid side inverter is a standard PWM voltage source inverter with a switching frequency of 2$\mathrm{kHz}$. The DC link voltage is regulated at $500 \mathrm{~V}$ with a DC capacitor of $2000 \mu \mathrm{F}$.

\subsection{Wind Variation}

The first simulations demonstrate the performance of the optimal power tracking system under varying wind speed.

Changes in wind speed are represented by varying the mechanical torque from 0.6 p.u. (average wind speed) to 1.0 p.u. (high wind speed resulting in maximum power capture).

The corresponding power output from the SRG is initially around $3.5 \mathrm{~kW}$ (Figure 7(a)). Figure 7(f) demonstrates $I_{r e f}$ set at 9 A by the power tracking system, the current hysteresis controller regulates the phase current well with an overshoot of $0.5 \mathrm{~A}$.

After $0.2 \mathrm{~s}$ the mechanical torque begins to increase to 1.0 p.u. and the system reaches steady state at $1.7 \mathrm{~s}$. The variation in the SRGs generated power is now around 6 $\mathrm{kW}$. 

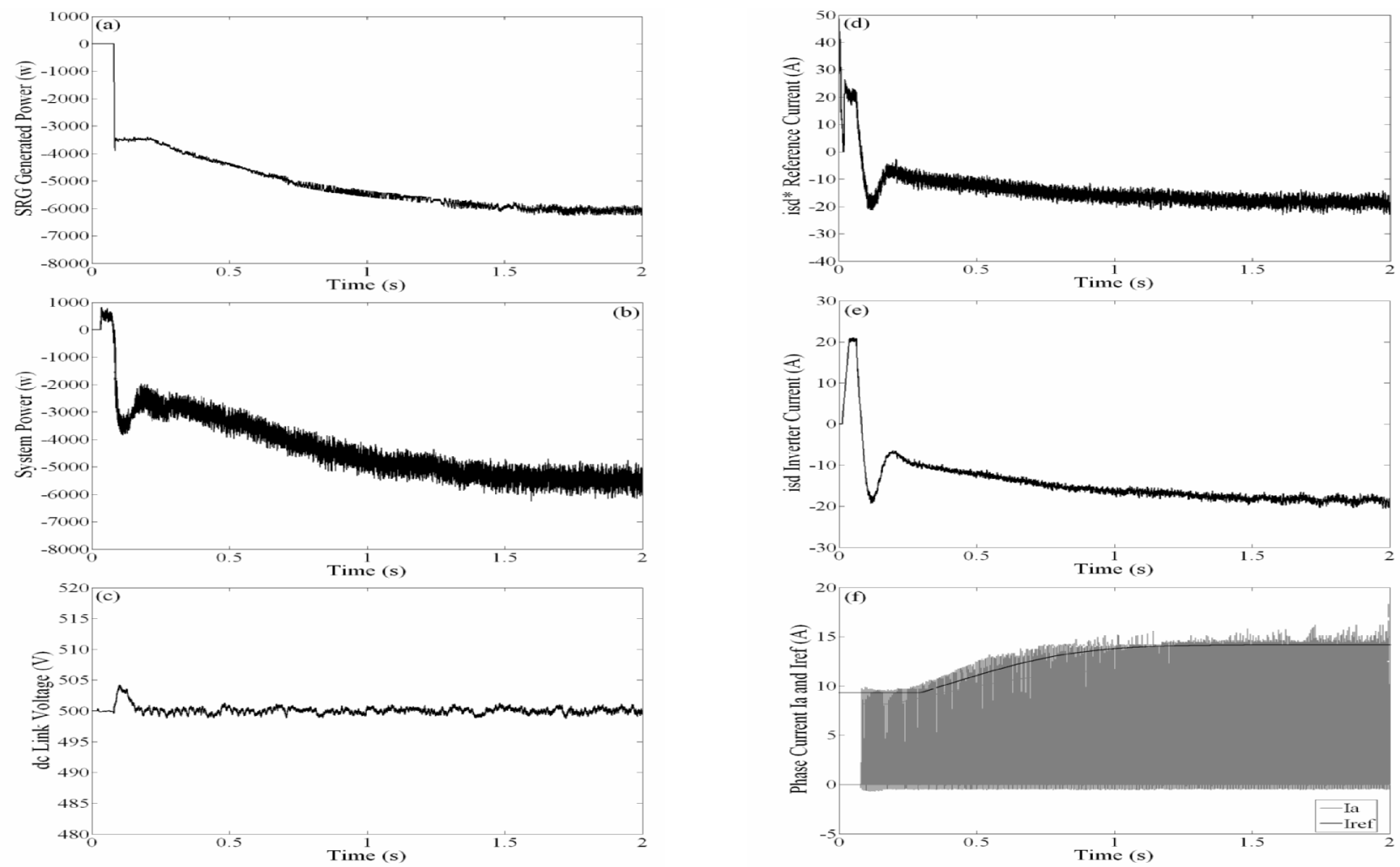

Figure 7 Simulation Results for Wind Speed Variation (a) SRG Generated Power. (b) System Power. (c) DC Link Voltage. (d) Inverter Reference Current $i_{s d}{ }^{*}$. (e) Inverter $i_{s d}$ current. (f) SRG Phase Current and Reference Current.
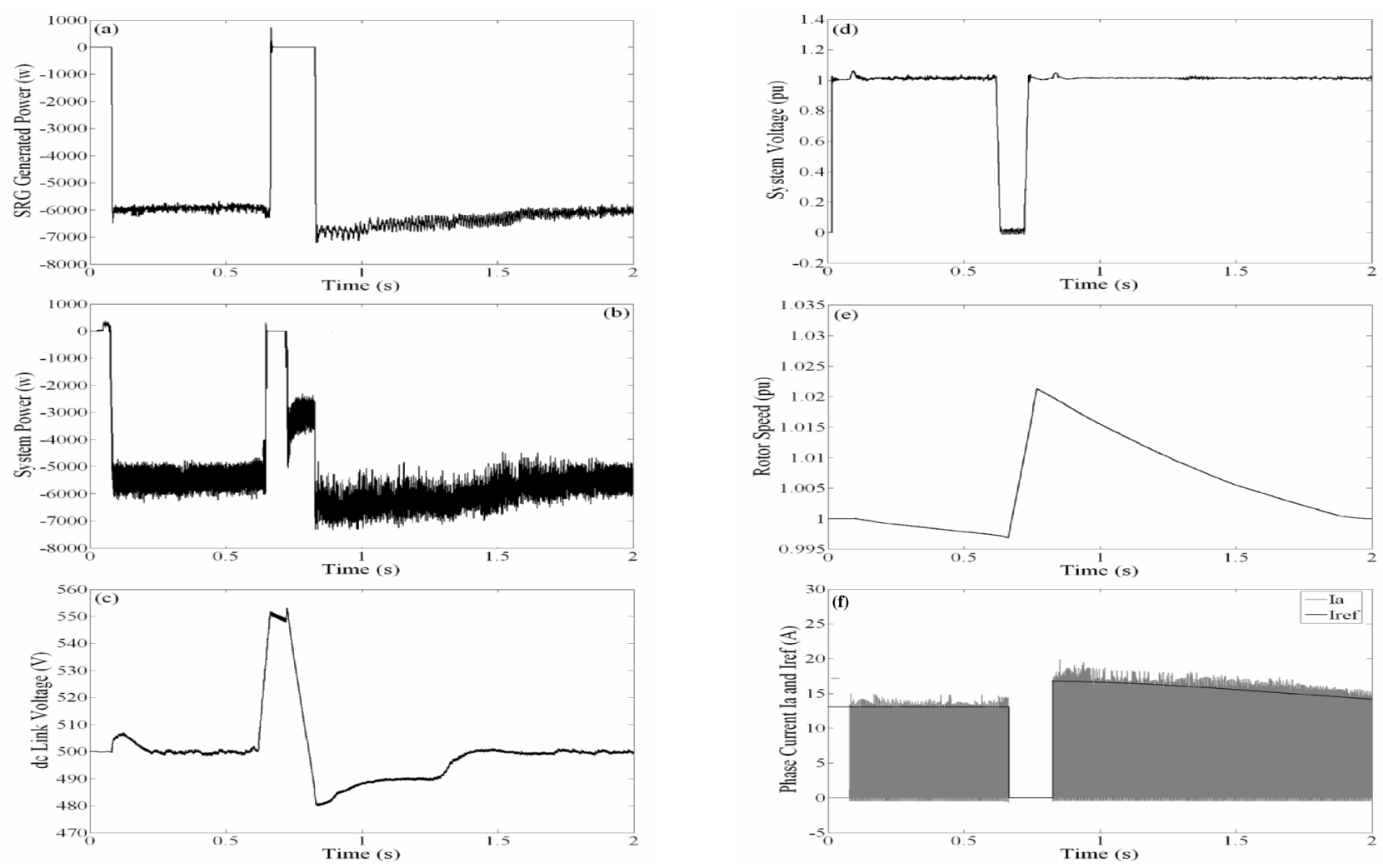

Figure 8 Simulation Results for Fault Analysis (a) SRG Generated Power. (b) System Power. (c) DC Link Voltage. (d) System Voltage. (e) SRG Rotor Speed. (f) SRG Phase Current and Reference Current. 
Figure 7(c) shows the DC link voltage regulated by the grid side inverter. The performance of the converter was satisfactory with very small variation throughout the change in wind speed.

Figure 7(d) shows the waveform of the reference current determined by the DC voltage control loop of the inverter. As expected, the variations in system power (Figure 7(b)) are followed by the reference current. The inverter's $i_{s d}$ current, in Figure 7(e), follows the reference current as expected and power exported to the system remains balanced with an average power of 3 $\mathrm{kW}$ for a mechanical torque of $0.6 \mathrm{p} . \mathrm{u}$. and average power of $5.5 \mathrm{~kW}$ for 1.0 p.u.

\subsection{Fault Analysis}

A balanced three-phase fault was applied to the system whilst the SRG was operating at maximum wind speed (mechanical torque of 1.0 p.u.).

The system was initially in steady state when a fault was applied at $6.2 \mathrm{~s}$. Due to the sudden decrease in system voltage, the system power reduced immediately (Figure 8(b)). Consequently, as shown in Figure 8(c) the DC link voltage began to rise. When the DC voltage reached $10 \%$ of the nominal value, the SRG fault hysteresis controller was enabled. The fault hysteresis controller applied a zero $I_{\text {ref }}$ (Figure 8(f)) and it can be seen from Figure 8 (a) that the power generated by the SRG was limited to almost zero. As expected the SRG now effectively acted as a DC voltage controller and prevented the voltage rising any further, (Figure $8(\mathrm{c})$ ). The electrical torque of the SRG was also reduced during fault. As the mechanical torque was now much greater than the electrical torque the rotor accelerated, as can be seen in Figure 8(e).

When the fault was cleared after $100 \mathrm{~ms}$ the system voltage began to rise, as shown in Figure 8(d). As $i_{d}$ was still limited to $0.5 i_{d \max }{ }^{*}$ the system power began to increase, (Figure 8(b)). With the sudden increase in system power and the SRG still limiting the generated power, the DC voltage began to fall as demonstrated in Figure 8(c).

When the DC voltage reached $-4 \%$ of its nominal value, the fault hysteresis controller passed control of $I_{r e f}$ to the optimal power tracking module. As can be seen from Figure 8(f), $I_{\text {ref }}$ was large due to the high rotor speed.

As the generated power was no longer limited by the fault hysteresis controller the electrical torque of the SRG was now greater than the mechanical torque and the rotor began to decelerate as shown in Figure 8(e).

The DC voltage recovered to $500 \mathrm{~V}$ at $1.7 \mathrm{~s}$ and the system returned to steady state at $1.9 \mathrm{~s}$.

\section{CONCLUSIONS}

The control system presented in this paper has shown how an SRG can be utilised as a variable speed wind turbine. Simulation results have demonstrated that the SRGs optimal power tracking capabilities for varying wind profiles is satisfactory.

In addition to the SRGs variable speed capabilities, simulation results have proved that with the proposed fault hysteresis controller, tripping of the SRG during a system fault is not necessary.

\section{REFERENCES}

1. Y. He, J. Hu and Z. Rende, "Modelling and Control of Wind-Turbine Used DFIG Under Network Fault Conditions" Proceedings of the Eighth International Conf. on Electrical Machines and Systems, vol. 2, pp. 986-991, Sept. 2005.

2. T.J.E. Miller, Electronic Control of Switched Reluctance Machines. Newnes Power Engineering Series, Oxford, U.K. 2001.

3. R. Cardenas, R. Pena, M. Perez, J. Clare, G. Asher, and P. Wheeler, "Control of a Switched Reluctance Generator for Variable-Speed Wind Energy Applications" IEEE Trans. Energy Conversion, vol. 20, no. 4, Dec. 2005.

4. R. Cardenas and R. Pena, "Sensorless Vector Control of Induction Machines for Variable Speed Wind Energy Applications" IEEE Trans. Energy Conversion, vol. 19, no. 1, Mar. 2004.

5. L. $\mathrm{Xu}, \mathrm{B}$. Andersen and P. Cartwright, "VSC Transmission Operating Under Balanced AC Conditions - Analysis and Control Design" IEEE Trans. Power Del., vol. 20, no. 1, pp 427-434, 2005.

\section{AUTHOR'S ADDRESS}

The first author can be contacted at:

School of Electronics, Electrical Engineering and

Computer Science

Queen's University Belfast

Ashby Building

Stranmillis Road

Belfast

BT9 5AH

Northern Ireland

Email-dmcswiggan02@qub.ac.uk 